\title{
THREE INSTITUTIONS, THREE APPROACHES, ONE GOAL: ADDRESSING QUALITY ASSURANCE IN ONLINE LEARNING
}

\author{
Marwin Britto \\ University of Saskatchewan-University Library \\ Cristi Ford \\ University of the District of Columbia—Research Academy for Integrated Learning \\ Jean-Marc Wise \\ Florida State University - Office of Distance Learning
}

\begin{abstract}
The rapid growth of online academic programs in higher education has prompted institutions to develop processes and implement strategies to ensure the quality of their online offerings. Although there is no one-size-fits-all approach, there are quality standards that institutions can effectively implement regardless of context. This paper examines the approaches of three different types of institutions in addressing quality assurance in online education on their respective campuses. Specifically, this paper presents three case studies and describes each institution's (1) background and overview, (2) definition of quality, (3) general approach to quality assurance, (4) models and strategies, (5) goals, (6) successes, (7) challenges, and (8) lessons learned. A comparison reveals that despite differences in scope, size, location, mission, and extent of online development, there is consistency in the institutions' strategies to addressing quality assurance in online learning.
\end{abstract}

\section{KEYWORDS}

Quality assurance, online learning

\section{INTRODUCTION}

Despite the continuous growth of online learning programs in all academic sectors, there is still some uncertainty about the quality of online educational programs at higher education institutions [1, 2]. With the proliferation of online learning initiatives in higher education, such as massive open online courses (MOOCs), it is critical that the issue of quality be effectively addressed [3]. Institutional oversight of quality in online learning programs is a key factor to programmatic success [4]. Over the past decade, a number of benchmarks and rubrics have emerged through organizations such as the Sloan Consortium (see www.sloanconsortium.org) and Quality Matters (see www.qualitymatters.org), which offer guidelines and processes for assessing and delivering quality in online learning programs [5]. However, further research is needed to identify and document the evidence of the process management of online quality assurance at the institutional level. Accordingly, this article examines the quality assurance processes and metrics at three diverse higher education institutions that vary in size, student demographics, location, mission, and degree of development of online learning programs. As practitioners continue to seek insight regarding the process of quality assurance of online learning programs at multiple levels, this article describes the context, challenges, success, and metrics that define quality.

\section{A. Context}

Quality assurance evaluations of online programs can be achieved using several methods. However, determining the quality of the actual process can be achieved in one of two ways (or both): benchmarking 
and specification of standards [2]. Benchmarking compares an institution's process and performance in an operational environment against a similar setting. Benchmarking takes into account the use of best practices across multiple institutions. Assessing quality by a specification of standards provides a baseline that can be used as a referenced set of criteria during the evaluation of performance. In online education today, the Sloan Consortium and Quality Matters are two organizations that provide specifications of standards that are often referenced as the primary guides for evaluating quality assurance. Sloan Consortium's central mission is to help organizations improve the quality of online education, but more specifically they provide the framework that enables institutions to focus on the "five pillars of quality" in higher education that can support quality online learning environments, namely (1) learning effectiveness, (2) scale, (3) access, (4) faculty satisfaction, and (5) student satisfaction [6]. In addition, Sloan offers oversight of quality through the Sloan Quality Scorecard, which allows administrators to engage in an evaluation of their online programs using seventy quality indicators. Quality Matters [7] is a peer-review approach to continuous improvement in online education and student learning that allows programs to review with thoughtful intent the course design process using a set of eight general standards developed from research on student engagement and systematic instructional design. The standards include (1) course overview and introduction, (2) learning objectives, (3) assessment and measurement, (4) instructional materials, (5) learner interaction and engagement, (6) course technology, (7) learner support, and (8) accessibility.

Online course quality has traditionally been reviewed for relevance to the learner by assessing course design, learning resources, and the course delivery process [2]. Moreover, institutions have been exploring metrics to compare the academic rigor and the integrity of online courses to their face-to-face counterparts [3]. The quality evaluation process takes into account the process at different levels ranging in scope from macro, such as the institutional oversight, down the micro level of student experience, such as offering support in orienting the student to the online learning environment through the types of engagement being offered in the course delivery [6]. This article highlights three case studies that document and compare the processes and quality assurance metrics at three higher education institutions, and describes the similarities and differences in their strategies, challenges, and opportunities for success.

\section{CASE STUDIES}

\section{A. Lone Star College System}

\section{Background and Overview}

The Lone Star College System (LSCS) is a multicampus community college system located in the north Houston area. LSCS serves students across 1,400 square miles spanning two counties in Texas. The system is comprised of six colleges, five campus centers, and two university centers and supports eleven K-12 school districts. LSCS is the largest community college system in Houston, and in 2012 was named the fastest-growing community college in the United States [8], with the greatest growth experienced in online student enrollment. Of the 90,000 students enrolled at Lone Star during the spring semester of 2013, more than 32,700 students were enrolled in 1,748 online courses taught by almost 900 online faculty. As of 2013, 35 certificates or degree programs are offered completely online.

Lone Star College-Online (LSC-Online) is a system-wide service and support department responsible for providing ongoing support and resources to all online students and faculty. Although the department does not have academic authority or academic purview, it does serve several important functions. These include (1) offering guidance and training in designing and delivering highly effective and engaging online courses; (2) collaborating with and engaging academic administrators and faculty through the Online Learning Council (consisting of Vice Presidents of Instruction and Faculty Senate Presidents from each of the six college campuses) in matters including quality assurance in online learning; and (3) making recommendations for the development and modification of academic policies and procedures designed to enhance the teaching and learning experience for online students and faculty alike. 


\section{Defining Quality}

Most stakeholders in higher education would agree that precisely defining the term "quality" and reaching any sort of consensus on its description are quite challenging. Consequently, many institutions generally use best practices and accepted benchmarks to approximate a standard of quality. Lone Star is no exception. The responsibility for and oversight of defining academic quality at Lone Star rest on the shoulders of the system-wide and campus-based academic administration who have been provided the authority, knowledge, and resources to design and shape these quality efforts on their respective campuses. Accordingly, each campus implements a variety of quality assurance measures for online courses, such as online course reviews and academic approvals, and the use of Quality Matters for course design.

\section{Quality Assurance}

Student success and completion are the highest priority at Lone Star College, and quality assurance is an integral component of achieving these goals. The Office of Research and Institutional Effectiveness has launched a system-wide initiative of Continuous Quality Improvement to assist campuses and departments in designing and implementing plans to optimize academic quality in academic programs and support departments. In 2012, LSC-Online designed a Continuous Quality Improvement model, which the Executive Director of LSC-Online entitled Quality by Design, or QbD.

\section{Models and Approaches}

LSC-Online's QbD model, as shown below in the Lone Star design in Figure 1, provides a framework for continuous quality improvement. The structure of this design, based on Sloan's five pillars of quality in online education [9], signifies a level of interdependence between each of the five components - or star arms - that are integral parts of a greater whole. In the QbD framework, each of the five components is organized around four categories: (1) a goal, (2) a process or practice, (3) a metric, and (4) progress indices. The model is designed to evolve over time as data are collected to establish what works well and what does not.

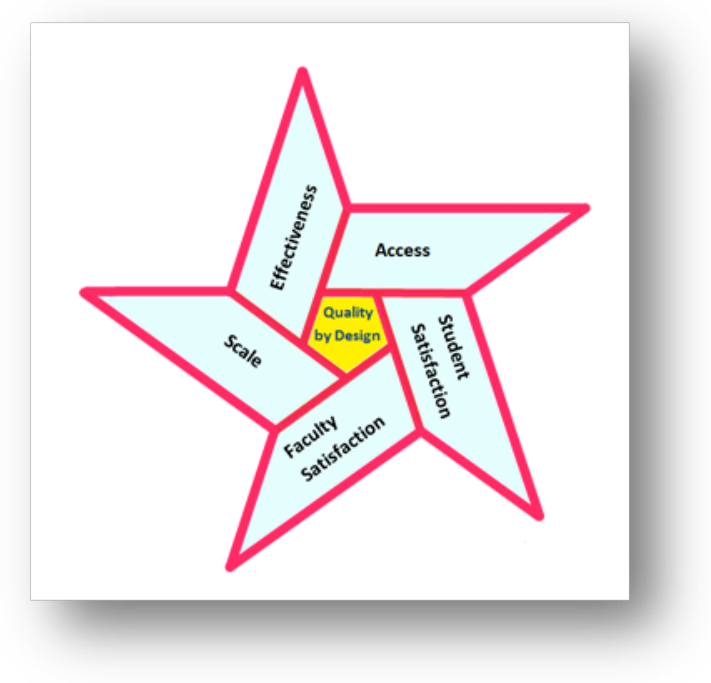

Figure 1. LSC-Online's Quality by Design-A Continuous Quality Improvement Model

The model's name, Quality by Design, reflects that the alignment of these five components to quality is intentional, deliberate, and planned. While some institutions may choose to commit resources to just one or a few of these components, LSC-Online's philosophy is that all components are essential for a successful online learning experience. Consequently, LSC-Online's commitment is to achieve a high level of quality in all five areas. In order to do this, a systematic and systemic approach is imperative. The model is systematic in the sense that each of these components will address quality standards and metrics, 
and it is systemic in LSC-Online's understanding that each of these components is interrelated, interdependent, and necessarily interactive with one another, and LSC-Online must plan its component strategies accordingly.

The first step in creating Lone Star's QbD model was to identify the quality standards for each of the five pillars or star arms in Figure 1, and then to identify or create the metrics through which they would be assessed. In some areas represented by these five components, quality standards and metrics already exist that may be appropriate to LSC-Online's context. Quality Matters, for example, used by several hundred higher education institutions in the United States, is a set of general and specific standards used to evaluate the design of online and blended courses. LSC-Online's instructional designers already use these standards as a guide for their instructional design process when partnering with faculty members to develop or improve online courses. The Quality Matters program falls under the "effectiveness" component of $\mathrm{QbD}$, and is one of several quality standards within this component.

\section{Goals}

In 2013, quality standards and benchmarks, along with their associated metrics, were identified, with each component aligned to one of Lone Star's Institutional Strategic Goals. Although great progress has been made in implementing this model, more work is needed to fully realize its value. The data points for each component highlight LSC-Online's strengths and weaknesses and help define a roadmap for improvement and innovation. The QbD model is predicated on the judicious use of these data for continuous quality improvement. Currently, LSC-Online's data largely exist in silos. The LSC-Online department has data from student support requests, faculty requests, student advising, etc. But it is not known how these interact and influence one another, nor is the data consistently used for improvement of support services. For example, does more and better quality training for online faculty, and/or do more extensive student support services online translate to better student performance, greater student satisfaction, and increased student completion, success, and persistence? The implementation of LSC-Online's Quality by Design framework seeks to answer these questions through the collection and attention to specific and aggregate data, and application of appropriate statistical analyses. The analyses of these data, known as analytics, will allow LSC-Online to identify areas for improvement, and adjust and re-allocate resources accordingly. A new Director of Client Relations and Quality Assurance position was created and filled in fall 2012. This individual coordinates, facilitates, and leads these efforts and will be instrumental in the further implementation and ongoing activities required by the Quality by Design model.

\section{Early Success}

Existing national benchmarks were useful for comparative purposes. For example, at Lone Star College, faculty who teach online must go through a self-paced Faculty Orientation: Online Teaching Certification program designed to prepare them to teach online. Anecdotal data suggest that LSC-Online's program takes faculty an average of two hours to complete. Nationally, in 2010 higher education institutions reported that they require their faculty, on average, to complete 22 hours of training (with a range of 1760 hours) before they can teach online courses [10]. Although LSC-Online has not determined how successful its faculty are in teaching online classes after completing Lone Star's required Faculty Orientation: Online Teaching Certification program, the significantly higher national average in faculty online training hours suggested that LSC-Online needed to take a closer look at the quantity and quality of its training and revise and improve its faculty certification program accordingly. Accordingly, in 2012 LSC-Online provided summer funding for 12 experienced online faculty to redesign the program based on an extensive review of the literature and soliciting best and exemplary practices in online teaching and learning from peers around the world. By spring of 2013, a newly designed model emerged, which used a cohort-model and mentor-facilitated 24-hour Online Teaching Certification and Faculty Mentoring Program. This program quickly gained support from faculty and campus academic administrators. Subsequently, it was approved by Lone Star's Executive Council for piloting in fall 2013 and full adoption in January 2014. 
Three Institutions, Three Approaches, One Goal: Addressing Quality Assurance in Online Learning

\section{Challenges}

As with any large, multicampus institution, getting faculty buy-in and support and building consensus with the appropriate stakeholders is a challenging and slow process. LSC-Online took almost eight months to garner the necessary support and approval to move forward the QbD initiative. Consequently, it became clear that it is crucial to build sufficient time into the overall process.

\section{Lessons Learned}

For the successful adoption of any initiative that may have a direct or indirect impact on faculty, it is imperative to include them as partners and advocates in the process from conception to implementation. It is equally important to identify and develop strategic relationships with those faculty and administrators who are opinion leaders and/or have influence and funding access. Even concepts that may be considered effective, efficient, and productive in higher education require the right mix of exposure, support, and approval to be successfully implemented, adopted, and sustained.

\section{B. University of the District of Columbia}

\section{Background and Overview}

The University of the District of Columbia (UDC) is an urban land-grant institution, a historically black college and university, and the only public institution of higher education in the District of Columbia in the United States. UDC offers associate, baccalaureate, and graduate degrees through its six colleges and schools. The total student enrollment at UDC is approaching 6,000 with nearly 80 percent from underrepresented minorities. Historically, the university has offered a small set (20-40) of online courses in programs across the campus.

UDC began using the Blackboard Learning Management System in 2004 due to faculty interest. While this was an early path for creating a strategic opportunity for faculty to utilize a learning management system, there was no concerted effort to formalize an online learning initiative at the university. In 2006, the Learning Resources Division and the Office of the Provost and Vice President of Academic Affairs commissioned an advanced Blackboard Users Workshop called Blackboard Scholars, through which 12 UDC faculty members were selected to create 10 high demand courses. By 2007, a pilot program entitled Faculty Course in Online Training (FCOT) was created. FCOT was a comprehensive in-house online training and certification program that was conducted from January to December 2007. The FCOT program trained and certified 17 UDC faculty members from multiple disciplines (e.g., Business, History, English, Education, Sociology, and Criminology).

By 2009, the Center for Academic Technology was formed to offer strategic and centralized guidance to UDC faculty members with regard to the online opportunities at the university. During this time, there was a formalized focus on policy and process flow in a concerted effort to improve the quality and oversight of the development in new online courses.

As the demand for high quality online teaching and learning continues to grow at UDC, there is an increased need for a more engaged, experiential and "deep learning" approach to training our faculty [11]. In response to these requests and in an effort to assist faculty in establishing teaching methods unique to the needs of our learning community, the Research Academy for Integrated Learning (RAIL) was formed. Specifically, RAIL has been commissioned with the oversight and guidance of online education, but also with effectiveness in teaching and learning with respect to our face-to-face classrooms.

In 2012, a city council mandated a right-sizing effort requiring the institution to submit a plan to the DC Council that preserved the mission of the institution but also renewed the vision, enrollment, and relevance of programming for students.

\section{Defining Quality}

As the goal of the right-sizing plan was being actualized, the 20/20 strategic vision plan focused its emphasis on increasing online course offerings as a key element in providing efficient, cost-effective, 
high-quality online programs and courses that would draw new students to the campus. At UDC, online education serves the mission, vision, and values of the university by providing a flexible and convenient pathway to higher education for the people of Washington, DC. RAIL, as a part of the University's overall strategic plan and mission, is committed to improving the quality of all learning experiences at the institution, with the online learning environment being no exception.

\section{Quality Assurance}

RAIL fills a vital role as it pertains to the quality of online learning courses. While online courses are subject to the same scrutiny that face-to-face courses receive when being evaluated, RAIL offers additional structured guidance and support toward the quality of online, student-focused courses. End-ofterm evaluations are administered by RAIL with a specific focus on online education.

\section{Models and Approaches}

The metrics and standards developed to assess quality in all areas of online education are based on trends and national best-practice standards. As for many institutions, at the course level, the benchmark of excellence in course design is the use of the Quality Matters (QM) rubric [12]. The QM standards are used to develop a comprehensive process for the way new online and hybrid courses are developed and offered. All new courses are reviewed by internal peer reviewer teams to determine if the course is ready to be offered. Courses that do not pass the internal peer review process are pulled from the registrar's list and are not offered as online courses to students until feedback from the reviews is incorporated that reflects student engagement and a student-centered focus as defined by the Quality Matters rubric.

To support the infrastructure and quality of the policy process for online education at UDC, the Committee for Online Learning (C4OL) was established. The mission of C4OL is to develop and disseminate guidelines, policies, and procedures that facilitate online teaching and learning at UDC. As a committee, C4OL has established guidelines consistent with the standards set forth by the Middle States Commission on Higher Education and National Best Practices. In addition, the Committee for Online Learning will lead UDC's assessment practices of online course proposals and online courses, as well as guide the University's Institutional Strategic Planning Process for Online Learning. The body consists of faculty members representing academic colleges across the university's main flagship and community college campus.

\section{Goals}

The importance and value of the goals of quality assurance are in line with Vision 2020: the University of the District of Columbia's Strategic Planning Process. The Academic Affairs portion of the strategic plan offers several specific goals and strategic outcomes that focus on online education. Senior leadership is committed to increasing UDC's online footprint, but not at the expense of providing quality programs and courses. Additional strategic goals for quality assurance have been outlined in the RAIL department's strategic goals and initiatives. As of fall 2013, there is a strategic plan and development for offering fully online certificates, programs, and concentrations throughout the UDC system.

\section{Success}

The increased focus on quality has resulted in better teaching and learning experiences for both online faculty and students. As a result of defining quality metrics that considered the online student perspective, a robust online orientation was created that online students can access through a self-enroll option. Moreover, as a result of creating an environment that focuses on quality, online faculty have an opportunity to pursue three additional certification tracks. These new tracks are designed to enhance and broaden the faculty's online teaching skills while maintaining a consistent level of quality. The five certification tracks enable online faculty to actively participate in the quality process, which in turn contributes to an improved overall online learning teaching and learning experience at the university.

\section{Challenges}


Three Institutions, Three Approaches, One Goal: Addressing Quality Assurance in Online Learning

One of the most pressing challenges faced by RAIL, which serves as the central department for supporting the university in all aspects of online learning, has been the limited human resources to serve both the flagship campus and the branch campus of the community college. The two sites are in multiple locations, and continuing to offer strategic oversight of new online growth has been a challenge. In addition, in past years quality control and buy-in to the formalized quality assurance process has taken some time for all constituents to value and appreciate, and to understand its importance. However, increased buy-in from faculty and deans has just begun to take shape and is now gaining momentum.

Reorganizations of the current online learning division have offered opportunities for great success, but sustaining their momentum has also proved challenging. The current iteration of the department, RAIL, offers more strategic connections to university schools and colleges by working closely with academic deans and senior leadership to offer insights concerning continued growth.

\section{Lessons Learned}

For many faculty at UDC, the response to a need for quality oversight of new online programs has been interpreted as a long and difficult process. UDC knows now that continuing to build capacity and engaging faculty in conversations about quality in courses are central to increasing buy-in and adoption. With a greater emphasis from UDC's accrediting body on online education, the dialogue has shifted dramatically to allow faculty to understand and see the value of adhering to the stated polices or to offer alternative solutions that will meet the same objectives.

\section{Florida State University}

\section{Background and Overview}

Florida State University (FSU) is a state-funded research institution in Tallahassee, Florida, with more than 40,000 undergraduate and graduate students enrolled annually. Online teaching and learning at FSU started well over a decade ago and has been growing at a steadily increasing rate. Today, FSU offers more than 400 online courses and 30 online programs, with annual enrollments topping 30,000. One in every 10 students is taking at least one online course per semester, and one in every 20 students is enrolled in a fully online program. Students have a wide range of online degree and certificate programs to choose from, including business, communication, computer science, criminology, education, nursing, public safety and security, and social work, and new courses and programs are added every year.

As a tier-one research institution, FSU holds all programs and courses to very high standards, regardless of mode of delivery. Academic programs and individual courses pass through rigorous reviews at various administrative levels including program, department, college, and university, before they are approved for delivery. Faculty members who are assigned to teach online courses are held to the same standards as those teaching in the traditional classroom but receive special training and support in order to maximize their effectiveness online. Students are admitted based on the same criteria whether they enroll in online or campus-based programs, and they are all held to the same academic standards.

\section{Defining Quality}

The university distinguishes various aspects of quality, including course design, delivery, mentoring, administration, support services, and technologies. Together, these dimensions affect the overall quality of an online student's learning experience. While quality can be assessed using objective criteria and applicable standards, each student's experience is subjective and unique, and it may be biased because of key events or components of the course. For example, some students may perceive the quality of a particular course to be very high because it uses lots of interesting videos, while other students might rate that same course as low in quality because their Internet connection was not fast enough to show the videos in high definition. While a well-designed course, in theory, stands a greater chance of succeeding, it is the students' impression of the quality that ultimately drives the success of a course, rather than the score it receives on an objective, criterion-based course review. Quality, therefore, is a variable that must be assessed from different perspectives, and its definition consists of multiple dimensions. Consequently, 
the university does not use a single definition of the term but rather defines criteria and sets standards for critical factors that affect quality overall.

\section{Quality Assurance}

The university delegates much of the responsibility for quality assurance of teaching and learning to the academic departments, which in turn adhere to field-specific accreditation requirements and applicable professional standards. Program directors and department chairs typically coordinate the goals and objectives of programs, and individual faculty members take responsibility for the quality of their own courses. Within this spirit of academic autonomy, faculty and university administration agree that high quality of courses and instruction is paramount, and the university has adopted policies and procedures that allow for specific checks and balances, including the use of university-wide, standardized course evaluations, quality enhancement reviews, and standardized forms and procedures for the approval of course syllabi and program specifications, to name but a few.

The Office of Distance Learning (ODL) fills an important role in the university-wide effort to ensure the quality of online courses and programs. Guided by a distance learning policy approved by the faculty senate along with a strategic plan, ODL uses a variety of methods and instruments to manage the development, implementation, delivery, support, and evaluation of all distance learning at FSU. However, given the relative autonomy of the faculty, activities of the office are typically based on voluntary participation encouraged by funding for course development, awards for excellence, and individual support.

\section{Models and Approaches}

The criteria established for the assessment of quality in each dimension are based on relevant theories and best practices. For example, course design is evaluated according to the principles of systematic instructional design. These principles form the foundation of the QM rubric [12], which is used in two ways to assess the quality of online courses. A first review focusing on the most critical standards of the rubric is conducted at the end of the course development phase. Formative feedback is provided in terms of comments from three reviewers in addition to the ratings of each standard. After a course has been taught at least once, a full review is conducted using the complete QM rubric. Suggestions for improvement of the course design are shared with the instructor and the course is logged as having been approved unless substantial changes are required. 


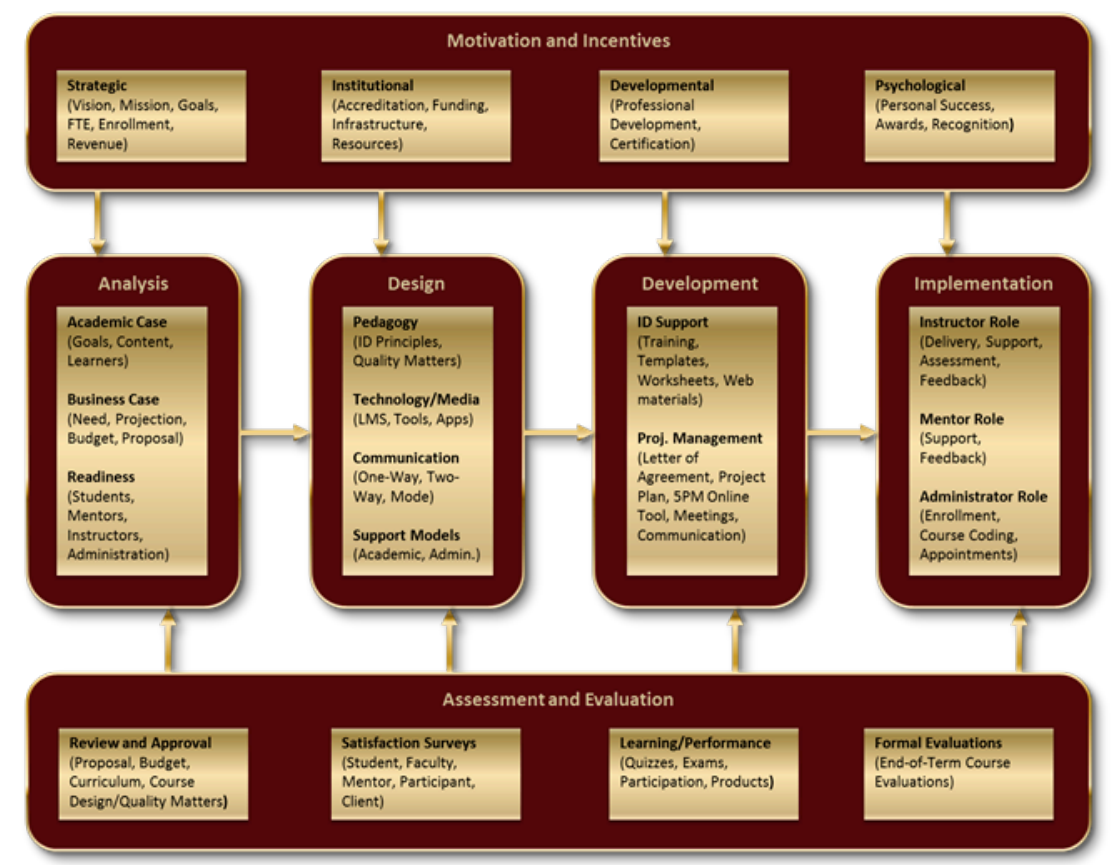

Figure 2. Quality Assurance Model, Office of Distance Learning, FSU

Quality assurance is guided by a comprehensive model (see Figure 2) that aligns instructional design and delivery activities with the strategic plan and includes specific assessments and evaluations for each step in the process. Course delivery is assessed by means of two instruments: (1) official, campus-wide course evaluations completed by students, and (2) additional end-of-term surveys focused on online courses and completed by faculty, course mentors, and students. The instruments consist of standard quantitative items as well as open-ended comments, which are analyzed for content and summarized in reports that are used to improve online course design and delivery. Feedback from these surveys is also used as input for improving instructor and mentor training and related information provided online. Additionally, the endof-term surveys include items assessing the quality of administrative, support, and technology services and products, and feedback is used to document effectiveness and make improvements as needed. Furthermore, new technologies in support of online course development and delivery are researched and evaluated on an ongoing basis.

\section{Goals}

The goals for quality assurance of online teaching and learning at FSU are in line with the university's overall strategic goals, which hold the quality of research and education at their core and underscore the importance of dedicating appropriate resources to ensure high-quality programs and courses [13]. The Office of Distance Learning Strategic Plan lists the determination of quality standards and best practices in instructional design and development, technology, student support, and assessment and evaluation as its first strategic goal [14]. Additional strategic goals further specify promoting the consistent use of standards and best practices in online teaching and learning as well as the use of innovative distance learning strategies and technologies. This ongoing effort ensures that online courses and programs at FSU are the result of research based instructional and pedagogical design and that they use innovative technology to offer online students an effective and stimulating learning environment.

\section{Successes}

The efforts of ODL have resulted in a series of online resources that systematically guide novice online instructors, course developers, course mentors, and students. Materials include guidelines, instructions, tutorials, and online courses that supplement individual consultations and support. Online instructors can 
download worksheets and templates that facilitate course design and development and ensure high quality results that are consistent with university policies and include up-to-date information.

FSU online courses are generally very well received, as evidenced by outstanding ratings and feedback in course evaluations and end-of-term surveys, as well as growing enrollments. Furthermore, instructors and mentors express their satisfaction with the training and support they receive and appreciate the resources that are available to them to ensure that the quality of their courses is consistently high. Every year, departments compete for ODL funding and support to help bring more courses and programs online. Similarly, the processes and policies developed to guide the administration of online courses and programs have proved effective. Streamlining the budgeting, finances, course listings, and registration within a single office for all academic departments that offer online courses and programs is essential to ensure consistency and avoid costly mistakes that could affect accountability, audits, and accreditation.

\section{Challenges}

Perhaps the greatest challenge in the case of FSU is to strike an adequate balance between preserving departmental and individual autonomy while at the same time ensuring that all online courses and programs offered at the university are of consistently high quality. The structure and governance of the university imposes limits on a centralized approach to quality assurance. Since the academic departments and colleges - and indeed the individual members of the faculty - enjoy a certain degree of autonomy concerning the choice of course content and delivery, the establishment and campus-wide adoption of shared standards is a sensitive topic and difficult to implement. Furthermore, the development of online courses is affected by this challenge in that ODL has limited authority to respond to the potential lack of cooperation and performance of subject matter experts and academic faculty assigned to development projects. Compensation for full-time academic faculty is governed by a collective bargaining agreement that does not allow compensation to be directly tied to their performance on a single project.

\section{Lessons Learned}

In response to the challenges described above, ODL is focusing on increasing individual support, customizing training, and highlighting and showcasing the benefits of following standards. In an analogy to Hersey and Blanchard's situational leadership model [15], academic faculty approach online course development from varying levels of readiness, and a personalized approach can be developed to provide the appropriate level of support and guidance during the development project. Professors experience the benefit of following the quality standards and guidelines by seeing their courses receive high scores on quality design reviews and receiving positive feedback and ratings in end-of-term evaluations.

Furthermore, excellence is encouraged and celebrated by a series of awards that provide opportunities for additional funding, recognition, and monetary rewards. Finally, the key to success is systematic design and project management. By setting precise goals, objectives, and standards along with specific deadlines for deliverables, projects are completed in a timely manner with high-quality products.

\section{CONCLUSION}

Quality assurance in online learning continues to be of interest to the research community. The focus of recent research on quality ranges from the use of individual technologies or instructional approaches to research on courses, programs, institutions, districts and regions, or entire countries [16, 17, 18, 19, 20]. A comparison of the three cases presented in this study showed that although the three institutions differ in size, focus, and culture, their approaches to assuring quality in online education are, in fact, surprisingly similar. First, the goals for quality assurance are aligned with the institutions' strategic plans, an approach that is well supported in the literature $[18,21]$. This critical aspect ensures that the efforts of the faculty and staff enjoy the support of the institution's leadership, sending a message that the quality of all educational programs is equally important regardless of delivery method. In addition, it demonstrates that the institution is prepared to invest adequate resources to ensure that online education meets appropriate standards. Second, all three institutions have developed initiatives to control the quality of online courses and programs across the system, and base their approaches on established models, including Quality 
Three Institutions, Three Approaches, One Goal: Addressing Quality Assurance in Online Learning

Matters [12] and Sloan's five pillars [9]. Their approaches are also similar in terms of offering support programs that lead to training and certification of online instructors, which is not only a best practice for promoting high-quality instruction in innovative contexts, but is becoming a shared standard of excellence in the context of institutional accreditation. The importance of the training and professional development of online instructors is also emphasized in the recent literature [22, 23]. Third, the three institutions are similar in that they feature centralized support units whose mission includes the development of appropriate quality standards as well as system-wide rollout, training, and evaluation to ensure that the standards are met. Centralizing the support function for distance learning is not uncommon [24].

Fourth, the three case studies also reveal that despite their differences, the institutions are facing similar challenges in their effort to promote high quality online education. Faculty buy-in was listed by all as a key challenge, which reflects a commonly observed tension in academia between the faculty and the administration [25]. Academic freedom is highly valued, especially in times when budgets are cut, affecting the quality of programs and courses and the ability of faculty to pursue their academic mission on independent paths. Centrally imposed systems that require faculty to reach consensus and conform to shared standards are regarded with suspicion and rarely welcomed. Competition is fierce in academia and members of the faculty are faced with competing priorities and a lack of adequate rewards for collaboration, leading them to develop an increased focus on individual achievements. In order for quality enhancement projects to succeed, faculty members have to be involved in the process and given an opportunity to help shape it. This conclusion is shared as an important lesson learned in all three cases in this study and is confirmed in other studies [26]. Furthermore, it is important to acknowledge that individual faculty members have different learning styles, needs, knowledge, abilities, and attitudes with respect to developing online courses and teaching online. In order to be effective, administrative units must provide a spectrum of support and professional development opportunities for individual faculty members.

Quality assurance at institutions of higher education is often a double-edged sword. On the one hand, it is evident that consistently high quality education requires shared standards, appropriate training, and adequate resources. In addition, accountability is critical across the institution, especially at institutions with relatively large numbers of faculty who have different levels of comfort and experience, and who may have competing priorities that prevent them from investing the time to learn and adopt the new technologies and pedagogies needed to succeed in online teaching. On the other hand, a diverse faculty forms the basis for a dynamic institution of higher education, where new knowledge is created and students are exposed to a variety of perspectives. Imposing artificial structures on faculty may have a stifling effect if they feel restricted or unnecessarily criticized regarding their ability to teach effectively. Effective management of these conflicting dynamics must focus on the benefits for faculty and their students rather than suggest that the individual's freedom must be sacrificed for the greater good. In order to achieve this result, faculty must experience direct, meaningful benefits from participating and be given an opportunity to embrace the suggested improvements as their own. Involvement in the design and implementation of shared standards is a prerequisite for this. Accordingly, support units should design high quality learning environments for online faculty and students, which foster collaboration, active learning and student engagement, and ultimately offer a common vision of excellence and opportunities for shared success.

\section{ABOUT THE AUTHORS}

Marwin Britto served as the Executive Director of Lone Star College-Online at the Lone Star College System until September 2013. He currently serves as the Associate Dean of the University Library at the University of Saskatchewan in Saskatoon, Canada. In addition, he has served in a number of administrative positions in higher education, and has had 10 years of university experience as a full-time faculty member. He has published and presented widely in academic journals and conferences in the areas of distance education/online learning, teaching and learning, teacher education, instructional technology, 
library science and change management. He holds four graduate degrees, including a $\mathrm{PhD}$ in Instructional Technology from the University of Georgia.

Cristi D. Ford is Director of the Research Academy for Integrated Learning (RAIL) at the University of the District of Columbia. This unit oversees all online learning programs for the university, as well as broader teaching and learning initiatives. She has expertise and experience in building new online learning programs and has an interest in research related to teaching and learning in the online environment. She has held several leadership positions in the online education realm and has served as a full-time and adjunct faculty member. She holds a PhD in Educational Leadership from the University of Missouri-Columbia.

Jean-Marc Wise is a faculty member at the Florida State University Office of Distance Learning and specializes in strategic planning, institutional effectiveness, online course design, assessment, and evaluation. He coordinates quality planning, design, and evaluation of distance learning courses and programs in support of academic departments. He has extensive experience in a wide range of educational technology and information systems and has been teaching in academic, nonprofit, and private sector contexts over the past two decades. He holds a PhD in Instructional Systems Design from Florida State University and is actively engaged in international collaboration and research projects.

\section{REFERENCES}

1. Lee, J. and Dziuban, C. Using Quality Assurance Strategies for Online Programs. Educational Technology Review, 10(2): 69-78 (2002).

2. Oliver, R. Quality Assurance and E-learning: Blue Skies and Pragmatism. Alt-J, 13(3): 173-187 (2005).

3. Chua, A. and Lam, W. Quality Assurance in Online Education: The Universitas 21 Global Approach. British Journal of Educational Technology, 38(1): 133-152 (2007).

4. Rovai, A.P. A Practical Framework for Evaluating Online Distance Education Programs. The Internet and Higher Education, 6(2): 109-124 (2003).

5. Mcloughlin, C. and Luca, J. Quality in Online Delivery: What Does It Mean for Assessment in Elearning Environments? In G. Kennedy, M. Keppell, C. McNaught \& T. Petrovic (Eds.), Meeting at the Crossroads. Proceedings of Australasian Society for Computers in Learning in Tertiary Education (ASCILITE): 417-426. Melbourne, Australia: Biomedical Multimedia Unit, The University of Melbourne (2001).

6. Moore, J.C. A Synthesis of Sloan-C Effective Practices. Journal of Asynchronous Learning Networks, 16(1): 91-113 (2011).

7. Quality Matters. About Quality Matters. (2013). https://www.qualitymatters.org/about

8. Pulsinelli, O. Lone Star College Breaks Record Enrollment. Houston Business Journal, September 18, 2012. http://www.bizjournals.com/houston/morning call/2012/09/lone-star-college-systembreaks.html

9. Lorenzo, G. and Moore J.C. Report to the Nation: Five Pillars of Quality Online Education. The Sloan Consortium (2002). http://sloanconsortium.org

10. WCET, and Campus Computing Project. Managing Online Education (2010). http://wcet.wiche.edu/advance/managing-online-education-survey

11. Bain, K. What The Best College Teachers Do. Harvard University Press: Cambridge, MA, 2004.

12. Quality Matters. Quality Matters Rubric (2013). https://www.qualitymatters.org/rubric

13. Florida State University. Florida State University Strategic Plan (2013). http://president.fsu.edu/content/download/83755/886586/

14. Office of Distance Learning. Office of Distance Learning Strategic Plan (2013). http://distance.fsu.edu/docs/admin docs/ODLStrategicPlan.pdf

15. Hersey, P. and Blanchard, K.H. Leadership Style: Attitudes and Behaviors. Training and Development Journal, 36(5): 50-52 (1982). 
16. Nandi, D., Hamilton, M., and Harland, J. Evaluating the Quality of Interaction in Asynchronous Discussion Forums in Fully Online Courses. Distance Education, 33(1): 5-30 (2012).

17. Mashaw, B. A Model for Measuring Effectiveness of an Online Course. Decision Sciences Journal of Innovative Education, 10(2): 189-221 (2012).

18. Miltenoff, P., Keengwe, J., and Schnellert, G. Technological Strategic Planning and Globalization in Higher Education. International Journal of Information and Communication Technology Education, 7(3): 51-61 (2011).

19. Cooper, S.B. A Closer Look at Distance Learning in the Kansas City, Missouri School District. Distance Learning, 9(2): 26-34 (2012)

20. Looi, C.-K., So, H.-J., Toh, Y., and Chen, W. The Singapore Experience: Synergy of National Policy, Classroom Practice and Design Research. International Journal of Computer-Supported Collaborative Learning, 6(1): 9-37 (2011).

21. Orr, R., Williams, M.R., and Pennington, K. Institutional Efforts to Support Faculty in Online Teaching. Innovative Higher Education, 34(4): 257-268 (2009).

22. Baran, E., Correia, A.-P., and Thompson, A. Transforming Online Teaching Practice: Critical Analysis of the Literature on the Roles and Competencies of Online Teachers. Distance Education, 32(3): 421-439 (2011).

23. Keengwe, J. and Georgina, D. The Digital Course Training Workshop for Online Learning and Teaching. Education and Information Technologies, 17(4): 365-379 (2011).

24. Kruger-Ross, M.J. and Waters, R.D. Predicting Online Learning Success: Applying the Situational Theory of Publics to the Virtual Classroom. Computers \& Education, 61: 176-184 (2013).

25. Baran, E., Correia, A.-P. and Thompson, A. Transforming Online Teaching Practice: Critical Analysis of the Literature on the Roles and Competencies of Online Teachers. Distance Education, 32(3): 421-439 (2011).

26. Herman, J.H. Faculty Incentives for Online Course Design, Delivery, and Professional Development. Innovative Higher Education, 38(5): 397-410 (2012). 
